\title{
Trigger of All Fingers in an 80 Years Old Male: A Case Report
}

\author{
*Md Sehal Khan Abid and Dr Pravin popatrav bande \\ MBBS (AMU) Dip in Orthopedics (AMU), DNB Orthopedics (BARC Hospital Mumbai), India
}

Received: October 21,2017; Published: October 27, 2017

*Corresponding author: Md Sehal Khan Abid, MBBS (AMU) Dip in Orthopedics (AMU), DNB Orthopedics, Bhabha Atomic Research Hospital, Mumbai 94, India, Tel: 7738905923, 9760739736; Email: drsehalkhanabid@gmail.com

\section{Introduction}

Trigger finger is a common condition with a reported prevalence of $2 \%$ to $20 \%$ [1,2]. Generally, trigger finger affects women more than men and the age distribution is bimodal with one group below six years of age and the other in their fifth and sixth decade of lif. It is a disorder which is associated with entrapment of the flexor digitorum superficialis or flexor digitorum profundus tendon along its course through fibro-osseous tunnels of the wrist, palm and digits of the hand [1]. Onset is usually gradual, associated with repetitive tasks, unaccustomed activity or compression of the pulley against hard objects. Snapping, clicking, locking, stiffness, and difficulty extending a flexed digit, often with discomfort or pain, are the most prominent symptoms $[3,4]$. Several studies suggest that individuals with type 1 diabetes, rheumatoid arthritis, carpal tunnel syndrome, arthritic changes in the wrist, hypothyroidism, mucopolysaccharidoses, amyloidosis, and congestive heart failure may be predisposed to flexor tendon entrapment [1].

The research on patients with trigger finger indicates various methods of treating patients including splinting, nonsteroidal antiinflammatory agents, percutaneous injection of corticosteroids, and surgical releas $[1,2,5]$. Very small, uncontrolled case series have shown in their results that only about half of patients are satisfied with their symptoms after a period of splint immobilization [6-8]. Triggering may resolve after one or two corticosteroid injections, but the results vary substantially between studies (35\% and 87 $\%$ for one and $72 \%$ to $92 \%$ for two injections) [9-13]. Various literatures suggest that patients should be informed about $50 \%$ success rates when offering a corticosteroid injection for trigger finger and that the chances of patients landing to surgical release still remains [14-16]. Percutaneous release has a success rate of $94 \%$ according to a recent systematic review of 2114 procedures but is accompanied by relatively high rates of complications like injury to nerves, injury to A2 pulley and bowstringing [17]. Open surgical release has a high success rate with few adverse events and is supposed to be the final treatment for trigger fingers $[18,19]$. We here present a case of trigger finger which has unique presentation but is successfully treated with open release.

\section{Case Report}

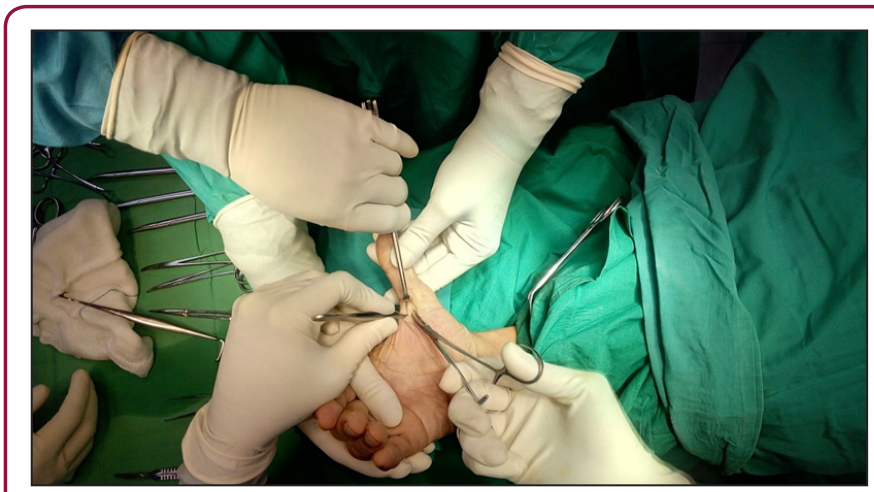

Figure 1: Release of A1 pulley of right thumb.

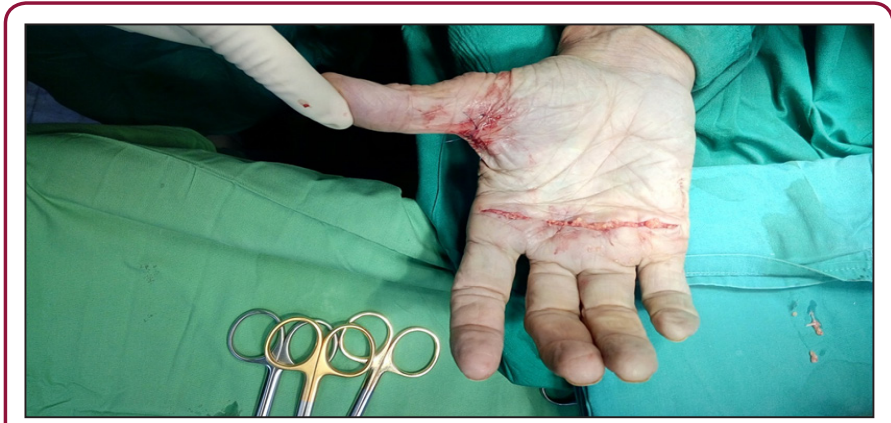

Figure 2 : Post surgical release of A1 pulleys of all fingers in right hand.

An 80 years old male patient presented to our OPD with triggering of both thumbs and middle finger of left hand. The patient had no co morbidities like diabetes, hypertension, or hypothyroidism and hence was advised percutaneous steroid injections along with analgesics and relative splinting. 2 weeks after the injection he was relieved of his symptoms in left thumb and middle finger but right thumb was still affected. The patient was advised 2nd dose of subcutaneous steroid injection along the 
flexor tendon sheath and A1 pulley of right thumb but his symptoms still persisted. As the patient was still reluctant to undergo surgical release he was offered splinting and relative rest to the thumb. After 2 months of initial presentation he again present to our OPD with triggering and pain at A1 pulleys of all fingers in right hand and remaining 3 fingers in the left hand. He was finally operated with release of A1 pulley of all fingers in right hand and steroid injections in left hand. After 3 months of surgery the patient was doing well with good finger grip and no pain or restriction of movements. The operative pictures and surgical approach has been shown in (Figures 1 \& 2).

\section{Discussion}

The present case is unique in itself with only one case reported till date as triggering of 10 fingers [20]. Although the presentation was gradual and the treatment was staged with physiotherapy, steroid injection and finally with surgical open release but eventually all the fingers were involved in a period of 3 months and they needed some form of intervention. Two out of three fingers which were initially treated by steroid injections were cured with no symptoms after 3 months of presentation. This result is similar to the published data about the efficacy of steroid injections in treatment of trigger fingers [9-11]. Patients who have recurrence or treatment failure with steroid injections are usually seen to opt for surgery in the first place, if other fingers are involved. Similar is the situation in our case where the patient opted for surgical release when remaining fingers were involved.

Trezies et al. investigated the occupational histories of 178 patients with idiopathic trigger fingers and they demonstrated no significant difference between the occupational distribution of patients with trigger digits and that of the general population [21]. They concluded that occupation may have a role to play in triggering of digits but many patients develop trigger for reasons other than occupation. Weilby concluded that anatomic and intrinsic factors, contribute to a predisposition for the development of tendon entrapment of the hand [22]. Our patient was a male who did not have any predisposing factors such as thyroid disease, diabetes, renal disease, connective tissue disorders, gout or rheumatoid arthritis. The unusual presentation of this patient at the age of 80 years with no positive family history and with no occupational predisposition for trigger finger makes this case unique in itself.

\section{Conclusion}

Trigger finger is a condition characterized by fibrocartilagenous metaplasia and hypertrophy of the surrounding structures of the flexor tendon resulting in a painful and debilitating restriction of motion. Flexor tendinopathy could be multi-factorial including anatomical variations of the pulley system and biomechanical etiologies. This could be exposure to shear forces and unaccustomed activity. Conventional treatment aims at decreasing inflammation through corticosteroid injection or surgically removing imposing tissue. Steroids although serve as a non surgical means to relieve the patient of symptoms, but have a limited role in multiple trigger digits presenting at one setting.

\section{References}

1. Moore JS (2000) Flexor tendon entrapment of the digits (trigger finger and trigger thumb). Journal of Occupational \& Environmental Medicine 42(5): 526-545.

2. Maneerit J, Sriworakun C, Budhraja N, Nagavajara P (2003) Trigger thumb: results of a prospective randomised study of percutaneous release with steroid injection versus steroid injection alone. J Hand Surg Br 28(6): 586-589.

3. Bayat A, Shaaban H, Giakas G, Lees VC (2002)The pulley system of the thumb: anatomic and biomechanical study. J Hand Surg 27(4): 628-635.

4. Howitt S, Wong J, Zabukovec S (2006) The conservative treatment of Trigger Thumb using Graston Techniques and Active Release Techniques $^{\circledR}$. J Can Chiropr Assoc 50(4): 249-254.

5. Makkouk AH, Oetgen ME, Swigart CR, Dodds SD (2007) Trigger finger: etiology, evaluation, and treatment. Curr Rev Musculoskelet Med 1(2): 92-96.

6. Colbourn J, Heath N, Manary S, Pacifico D (2008) Effectiveness of splinting for the treatment of trigger finger. J Hand Ther Off J Am Soc Hand Ther 21(4): 336-343.

7. Lindner Tons S, Ingell K (1998) An alternative splint design for trigger finger. J Hand Ther 11(3): 206-208.

8. Patel MR, Bassini L (1992) Trigger fingers and thumb: when to splint, inject, or operate. J Hand Surg 17(1): 110-113.

9. Anderson B, Kaye S (1991) Treatment of flexor tenosynovitis of the hand (trigger finger) with corticosteroids. A prospective study of the response to local injection. Arch Intern Med 151(1): 153-156.

10. Benson LS, Ptaszek AJ (1997) Injection versus surgery in the treatment of trigger finger. J Hand Surg 22(1): 138-144.

11. Dala-Ali BM, Nakhdjevani A, Lloyd MA, Schreuder FB (2012) The Efficacy of Steroid Injection in the Treatment of Trigger Finger. Clin Orthop Surg 4(4): 263-268.

12. Peters Veluthamaningal C, Winters JC, Groenier KH, Jong BM (2008) Corticosteroid injections effective for trigger finger in adults in general practice: a double-blinded randomised placebo controlled trial. Ann Rheum Dism 67(9): 1262-1266.

13. Lambert MA, Morton RJ, Sloan JP (1992) Controlled study of the use of local steroid injection in the treatment of trigger finger and thumb. J Hand Surg Edinb Scotl 17(1): 69-70.

14. Becker SJE, Braun Y, Janssen SJ, Neuhaus V, Ring D, et al. (2015) Early Patient Satisfaction with Different Treatment Pathways for Trigger Finger and Thumb. J Hand Microsurg 7(2): 283-293.

15. Ring D, Lozano Caldero NS, Shin R, Bastian P, Mudgal C, et al. (2008) A prospective randomized controlled trial of injection of dexamethasone versus triamcinolone for idiopathic trigger finger. J Hand Surg 33(4): 516-522.

16. Wojahn RD, Foeger NC, Gelberman RH, Calfee RP (2014) Long term outcomes following a single corticosteroid injection for trigger finger. J Bone Joint Surg Am 96(22): 1849-1854.

17. Zhao JG, Kan SL, Zhao L, Wang ZL, Long L, et al. (2014) Percutaneous first annular pulley release for trigger digits: a systematic review and meta analysis of current evidence. J Hand Surg 39(11): 2192-2202.

18. Lange Riess D, Schuh R, Hönle W, Schuh A (2009) Long term results of surgical release of trigger finger and trigger thumb in adults. Arch Orthop Trauma Surg 129(12): 1617-1619.

19. Lim MH, Lim KK, Rasheed MZ, Narayanan S, BengHoi Tan A (2007) Outcome of open trigger digit release. J Hand Surg Eur 32(4): 457-459.

20. Lee YK, Kam BS, Lee KW, Kim WJ, Choy WS (2007) Ten Trigger Fingers in an Adult Man : A Case Report. J Korean Med Sci 22(1): 170-172. 
21. Trezies AJ, Lyons AR, Fielding K, Davis TR (1998) Is occupation an aetiological factor in the development of trigger finger? J Hand Surg Edinb Scotl 23(4): 539-540.
22. Weilby A (1970) Trigger finger. Incidence in children, adults and the possibility of a predisposition in certain age groups. Acta Orthop Scand 41(4): 419-427.

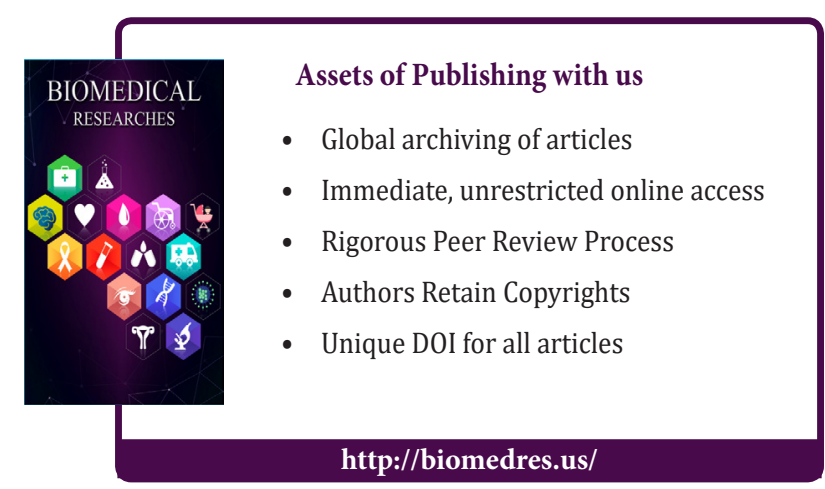

